\title{
Sobre algunos elementos del contorno en el diccionario fraseológico
}

\author{
JUAN A. MARTÍNEZ LÓPEZ \\ Universidad Noruega de Ciencias Empresariales (NHH)
}

\section{INTRODUCCIÓN}

Una de las características fundamentales de la lexicografía moderna es su tendencia a la especialización, a fin de adaptarse a las necesidades de sus usuarios naturales. En este sentido no es difícil advertir que la elaboración de los diccionarios se realiza tomando en consideración ciertas pautas como el nivel de especialización, tamaño, alcance de las ilustraciones e, incluso, las características del público al que va dirigido un determinado trabajo. En lo que respecta a esto último, cabe destacar el esfuerzo que durante los últimos años -especialmente a remolque del desarrollo de la lexicografía en lenguas como el francés o el inglés- se viene realizando en relación con los diccionarios pedagógicos, y en particular con los denominados diccionarios escolares. Pese a que todos ellos persiguen un fin didáctico, de entre los pedagógicos se pueden establecer dos grandes grupos: por un lado los dirigidos a estudiantes que se están formando en su lengua materna; y por otro, los dirigidos a aquellos interesados en una lengua extranjera.

Tradicionalmente, los diccionarios han consistido en la compilación del léxico de una lengua, tomando como unidad la palabra. Sin embargo, recientemente, el auge de los estudios dedicados a la fraseología ha ido propiciando el que muchas de estas unidades pluriverbales -como son por ejemplo las locuciones- hayan ido tomando acomodo en el cuerpo de los diccionarios de lengua, al ser consideradas como unidades léxicas; esto es, conglomerados más o menos complejos de palabras que mantienen un significado global, generalmente al margen del significado léxico de sus componentes. Estas unidades pluriverbales han ido incorporándose al cuerpo de los diccionarios de modo poco exhaustivo y vacilante ${ }^{1}$, dada la falta de estudios prácticos de gran profundidad que tuviesen como objeto la recogida de material. Sin embargo, el problema mayor ha sido sin duda el intercalar tales unidades en un diccionario de lengua (de uso), cuyo planteamiento teórico y metodológico estaba orientado para el tratamiento de unidades monoverbales (vocablos) y no pluriverbales (unidades fraseológicas), lo que ha propiciado un cierto desfase entre la metodología y la heterogeneidad de los elementos tratados. Todo ello ha tenido como colofón el que muy recientemente algunos lingüistas y lexicógrafos hayan unido esfuerzos con el fin de desarrollar trabajos de lexicografía exclusivamente fraseológica utilizando métodos más acordes a la naturaleza de estas unidades pluriverbales. Así, viendo la necesidad de utilizar metodologías diferentes para cada tipo de léxico (monoverbal y pluriverbal), recientemente se han empezado a diseñar recopilaciones lexicográficas de carácter exclu-

\footnotetext{
${ }^{1}$ Este tema se trata en profundidad en el trabajo de Castillo Carballo (2001).
}

JUAN MARTínEZ, «Sobre algunos elementos del contorno en el diccionario fraseológico», Revista de Lexicografia, XIII (2007), pp. 55- 65. ISSN: 1134-4539, e-ISSN: 2603-667. DOI: https://doi.org/10.17979/rlex.2007.13.0.4785 
sivamente fraseológico. ${ }^{2}$ En algunos de estos diccionarios se han empezado a poner en práctica algunas de las necesidades ya apuntadas por Zuluaga (1992: 130):

Nos parece conveniente y útil describir sistemáticamente no solo el contenido semántico de cada UF sino también, especialmente en el caso de las locuciones, indicar la clase de construcciones que pueden formar y las clases de elementos con que se combinan. En otras palabras, un análisis más completo que los ofrecidos por diccionarios y compilaciones tradicionales debe señalar, además del contenido, las propiedades combinatorias de cada locución, o lo que es lo misno, su contexto verbal inmediato. Este contexto puede explicitarse en términos de clases léxicogramaticales y clases léxicosemánticas.

Otro aspecto de la lexicografía más tradicional -al que más adelante nos referiremosha sido su enfoque pedagógico; más destinado, por lo general, a la descodificación de los enunciados que a la producción de los mismos. No obstante, como excepción a dicha regla pueden considerarse hoy los diccionarios «de uso», pues, como se indica en el DUE, pretenden ser

[...] un instrumento para guiar en el uso del español tanto a los que lo tienen como idioma propio como a aquellos que lo aprenden y han llegado en el conocimiento de él a ese punto en el que el diccionario bilingüe puede y debe ser substituido por un diccionario en el propio idioma en que se aprende (1977: Presentación).

Más explícito aún es el GDLE, que tiene como una de sus prioridades el ser un instrumento tanto para el estudiante extranjero como para el profesor de lengua española, razón por la que en él se han incluido:

[...] aspectos lingüísticos exigidos por quien no es nativo de la lengua, es decir, tratará de dar respuesta a las preguntas que se hace normalmente quien, siendo extranjero, pretende aprender el español. Se trata, por tanto, de tener en cuenta lo que podría denominarse como una visión de la lengua desde fuera, desde el exterior (1985: Introducción).

En resumen, se observa cómo, de modo paulatino, la lexicografía ha comenzado a tomar conciencia de que en función de cual sea el prototipo de usuario el diccionario ha de reunir un particular enfoque pedagógico y metodológico.

\section{LA UNIDAD FRASEOLÓGICA: TIPOS Y CARACTERÍSTICAS}

Situándonos ya en el campo de la lexicografía fraseológica, se advierte que ésta presenta ciertos desajustes en relación con algunos aspectos teórico-metodológicos que, concebidos para la unidad léxica por antonomasia -la palabra-, no son los más adecuados para ser aplica-

\footnotetext{
${ }^{2}$ No obstante, algunos lingüistas han sugerido que las unidades fraseológicas no deberían ser inventariadas en repertorios independientes, ni incluidas al final del artículo del diccionario ya que, al ser funcionalmente palabras, deberían tener el mismo estatus que el resto de las entradas y ocupar el lugar que le corresponda de acuerdo con la ordenación establecida. Por supuesto, sin menoscabo de que «[...] la ortografía normativa preceptúe representar gráficamente estas unidades de manera discontinua, con elementos en blanco ente los componentes» (FernándezSevilla 1974: 21-22).
} 
dos a otros elementos de naturaleza y estructura más compleja como son las unidades fraseológicas. Dichos elementos se subdividen, según recientes estudios, en tres grupos básicos:

1. Colocaciones. Son sintagmas libres que presentan ciertas restricciones combinatorias acuñadas en el propio uso. Se trata, por tanto, de fijaciones en la norma: odio mortal, entablar amistad, etc

2. Locuciones. ${ }^{3}$ Unidades fijadas en el sistema que, sin ser enunciados completos, funcionan como elementos oracionales: cabeza de turco, de pascua a ramos, vivir del cuento, morder el anzuelo, etc.

3. Enunciados fraseológicos: Según Corpas Pastor (1996: 172): «[...] constituyen enunciados y actos de habla por sí mismos, además de estar formados en el habla y formar parte del acervo sociocultural de la comunidad hablante»: De casta le viene al galgo, que usted lo pase bien, a correr tocan, etc.

Recientementemente los diccionarios han comenzado a hacerse eco de la existencia de las llamadas colocaciones y de las dificultades que entraña su inserción en el cuerpo de las obras lexicográficas. ${ }^{4}$ Se trata de un grupo bastante heterogéneo si tenemos en cuenta su tipología y las relaciones entre colocante y colocado. ${ }^{5} \mathrm{~A}$ este respecto puede decirse que el denominador común de estas unidades pluriverbales lo constituye su alto índice de frecuencia de coaparición en el decurso sintáctico. No obstante, dicho indice de coaparición puede variar enormemente de unas unidades a otras: así, hay casos de altísima frecuencia en los que la existencia de una palabra exige la inclusión en el decuerso de la otra. Ello ocurre, al igual que en el ámbito de las locuciones, con las llamadas palabras «idiomáticas». ${ }^{6}$ Un ejemplo de esto lo tenemos en la palabra «garrafal», cuyo uso implica hacer referencia a «error»o «fallo», las únicas palabras con la que combina en el discurso. ${ }^{7}$ En otros casos, la colocación queda más difuminada al abrirse las posibilidades combinatorias: «entablar» (amistad, guerra, batalla, relación, negociaciones, etc.). Como se observa, el abanico de las colocaciones forman un continuum que va desde la combinación en exclusiva hasta prácticamente la libre combinación. Desde el punto de vista semántico, por lo general, se trata de sintagmas bastante transparentes.

Los enunciadios fraseológicos tienen en común con el grupo anterior el constituir estructuras fijadas desde el punto de vista formal. Sin embargo, al tratarse de enunciados en sí

${ }^{3}$ Casares (1992 [1950]: 170) las definió como «Combinación estable de dos o más términos, que funcionan como elemento oracional y cuyo sentido unitario consabido no se justifica, sin más, como una suma del significado normal de los componentes».

${ }^{4}$ Un estudio sobre las dificultades que entraña la inserción de estas unidades en el ámbito de la lexicografía puede verse en Calderón Campos (1994)

${ }^{5}$ Hausmann (1979: 81-84) observó que los elementos formantes de la colocación no portan el mismo estatus, sino que es uno de ellos, el elemento base (basis) el que determina la existencia en el decurso del segundo formante, el colocado (kollokator). Por lo general son los núcleos de los diferentes tipos de sintagma los que actúan como bases, y los adyacentes, como colocados.

${ }^{6}$ De acuerdo con Zuluaga (1980: 102), por palabras idiomáticas entendemos las unidades léxicas formadas por un elemento lingüístico que, por diversas razones, aparece exclusivamente dentro del marco de una UF, y que por tanto funciona como signo diacrítico. El uso de estas palabras idiomáticas en la sincronía actual, queda estrictamente limitada a los casos en que intervienen como componentes de una unidad fraseológica, es decir, su aparición confirmará, de modo automático, el carácter fraseológico de la secuencia de que forma parte.

${ }^{7}$ Ello no implica que estas fuertes restricciones combinatorias no se den con unidades palabras no idiomáticas. De hecho la palabra fruncir solo es susceptible de combinarse con ceño, pese a no ser idiomática. 
mismos, quedan al margen de la lexicografía, entendida ésta en su sentido tradicional, esto es, como inventario del léxico de una lengua o de parte de ella. No obstante, el enfoque didáctico ha llevado a que se creen dos subgrupos de enunciados fraseológicos: el primero estaría formado por los refranes, adagios, etc., de estructura normalmente más complicada, a los que se tiende a agrupar en repertorios paremiológicos. El segundo estaría formado por unidades más breves, que sin ser paremias constituyen actos de habla. Son lo que Corpas Pastor (1996: 271) denomina fórmulas rutinarias: ¿Qué hay?, hasta luego, a eso voy, lo siento, ya lo creo, ni hablar, qué se le va a hacer, ja mí, plin!, largo de aquí, tú diras, etc. Estas unidade sí han ido incorporándose, en mayor o menor grado, a los diccionarios, tanto a los generales de lengua como a los fraseológicos.

Estos dos grupos de fraseologismos -las colocaciones y los enunciados fraseológicospresentan rasgos que los hace quedar fuera del análisis de este estudio: los primeros a causa de su alto nivel de transparencia semántica, por lo que no constituyen el grupo más relevante en un diccionario fraseológico. Los segundos por presentar una estructura petrifica que no permite intercalar a los actantes del discurso para actualizar su significado (al menos de forma explícita), es decir, por carecer de elementos del entorno tal como los concebimos en este trabajo.

El tercer grupo de fraseologismos lo constituyen las locuciones. Éstas son normalmente sintagmas oracionales desde el punto de vista formal, y unidades léxicas desde una perspectiva semántica. Este tipo de unidades pluriverbales cubre la casi totalidad de las categorías léxicas (a excepción de la que correspondería al artículo). Así, vemos que los equivalentes semánticos de los sustantivos son las locuciones sustantivas: cabeza de turco, año de la polca, mosquita muerta, etc., las equivalentes a adverbios, locuciones adverbiales: de higos a brevas, cuando las ranas crien pelo, gota a gota, etc. La diferencia fundamental entre este grupo y las colocaciones subyace, por lo general, en el significado. Mientras aquellas son transparentes, éstas presentan un mayor grado de opacidad.

De entre el grupo de las locuciones vamos a destacar dos tipos que presentan particularidades que las diferencian de las demás: nos referimos a las verbales: tomar [alguien] la de villadiego, dormir [alguien] la mona, cantar [alguien] las cuarenta [a alguien], y a las adjetivas: (estar) [alguien] hecho-a un brazo de mar, (estar) [alguien] en Babia, (ser) [alguien-algo] corriente $y$ moliente, etc. Dicha particularidad reside en que mientras las sustantivas, adverbiales, prepositivas y conjuntivas mantienen un significado ya en su propia definición, que no se ve afectado por la naturaleza de los actantes, las adjetivas -y en mayor grado las verbales- están sujetas a restricciones de uso en función de la naturaleza de los actantes que participan en el fragmento discursivo, así como a ciertos ajustes derivados de la necesidad de guardar concordancia.

\section{LA LEXICOGRAFÍA FRASEOLÓGICA}

El interés por esta particular modalidad de léxico - nos referimos a las expresiones fijas-, ha llevado muy recientemente a la confección de diccionarios exclusivos de carácter fraseológico, así como a trabajos de carácter didáctico centrados en el aprendizaje de las UF. ${ }^{8}$ No obstante los frutos de los trabajos ya realizados, el diseño de nuevos diccionarios de produc-

\footnotetext{
${ }^{8}$ Del primer tipo podemos destacar el Diccionario fraseológico del español moderno; el Diccionario de dichos y frases hechas o el Diccionario del español coloquial. Dichos, modismos y locuciones populares. Del segundo tipo, quizás los más representativos sean El español idiomático. Frases y modismos del español y La enseñanza de las unidades fraseológicas.
} 
ción dirigidos a hablantes extranjeros exige un permanente esfuerzo de mejora de una metodología peculiar e independiente, al menos en parte, que dé satisfacción a quienes se acercan a un diccionario para saber más y, sobre todo, cómo ha de utilizarse correctamente una determinada locución (Martínez Marín 1991).

Ciertamente, el objeto principal de un diccionario es la descripción de sentidos y usos de una palabra, o grupo de ellas. Para optimizar este fin, la lexicografía de hoy se fundamenta sobre un espacio multidisciplinar al que contribuyen diversas parcelas de los estudios lingüísticos. De acuerdo con Rey-Debove (1994: 31-32), podemos decir que de entre las obligaciones de la lexicografía destacan dos: por un lado, el sintetizar las investigaciones de los diferentes aspectos que atañen al léxico, como son la grafía, la pronunciación, propiedades morfosintácticas, propiedades semánticas, usos sociales, propiedades estilísticas, etc. Por otro, producir una obra de consulta que permita a los usuarios de la lengua tanto comprender las palabras como utilizarlas correctamente. ${ }^{9}$ Centrándonos ahora en el campo de la fraseología, los aspectos reseñados requieren un particular enfoque, dado que:

a) Las unidades tratadas son entes pluriverbales y no palabras independientes.

b) A diferencia de la «palabra» cuya forma está por lo general plenamente fijada, la UF presenta una fijación más que relativa, ${ }^{10}$ lo que presenta dificultades desde el momento de su lematización.

c) Dado que los formantes de la UF son palabras, éstas presentan una cierta adaptación al discurso donde se inserta -especialmente de las palabras que admiten flexión- que no es general en el conjunto de las UF.

d) Son muchas las unidades, especialmente en el grupo de las locuciones, susceptibles de variación de categoría léxica, a fin de adaptarse a las necesidades del entramado discursivo.

Procederemos a continuación a tratar un aspecto formal que debería tenerse en cuenta a la hora de lematizar un diccionario fraseológico destinado a aquellos usuarios, por lo general no hablantes nativos, que necesitan una mayor información sobre las restricciones combinatorias que presentan las UF al ser integradas en el discurso. Nos referimos al problema en torno a cómo dar cabida a ciertos elementos que, aún no formando parte de la unidad en sentido estricto, constituyen una función sintáctica obligada para el funcionamiento discursivo de dicha unidad. Nos estamos refiriendo a la función de sujeto o complemento de las llamadas locuciones adjetivas y verbales. Téngase en cuenta que el tratamiento o hincapié en algunos de estos elementos puede parecer innecesario para muchos hablantes nativos; sin embargo, un hablante de español como lengua extranjera necesita más información con el fin de saber con mayor concreción qué opciones le brinda la lengua y cuáles le están vedadas en el proceso de adaptación de las UF al decurso sintáctico

A este respecto, no es casual que, mientras los diccionarios generales de lengua plantean los lemas locucionales sin hacer hincapié en los elementos del entorno, como, por ejemplo: estar pez, dar la callada por respuesta, etc., algunos diccionarios de carácter exclusivamente fraseológico como el realizado por Varela y Kubarth (1994) han optado por señalar la naturaleza de dichos elementos mediante «u.p.» (una persona) y «u.c.» (una cosa): estar u.p. pez, dar u.p.

\footnotetext{
${ }^{9}$ Un tratamiento más concreto de los asuntos aquí expuestos puede verse en la amplia bibliografía al respecto de la que vamos a señalar algunos trabajos: Ahumada Lara (1989: 16), Lara (1979: 228), Cifuentes (1994: 165).

${ }^{10}$ Véase, a este respecto, García-Page (2001).
} 
la callada por respuesta, a sabiendas de la importancia que para un hablante extranjero tiene el hacer referencia a las funciones sintácticas, de carácter obligado, cuyo conocimiento es indispensables para un uso correcto de éstas en el decurso sintáctico.

\section{ELEMENTOS DEL CONTORNO EN EL MARCO LOCUCIONAL}

Pese a decirse por lo común que los hablantes tienen plena libertad de elección de palabras a la hora de construir su propio discurso, no son pocas las palabras que presentan restricciones a la hora de combinarse con otras. Estas restricciones pueden deberse tanto a factores semánticos como a sintácticos. En el marco de las UF, y más concretamente del locucional, la mayoría de las unidades están sujetas a determinadas funciones sintácticas ?sujetos o complementos? que son las que hacen viable dicha unidad o, en ocasiones, las que determinan que una unidad tenga en el decurso uno u otro significado. Por ello nos parece conveniente que tales expresiones vayan acompañadas de la información pertinente, teniendo en cuenta que al no ser elementos fijados de la expresión han de ir marcados con los recursos gráficos que pongan de relieve su naturaleza. Una forma precisa de marcar tales elementos ha sido el ponerlos entre corchetes. De esta forma, no solo se añade información precisa en cuanto a la estructura, sino que permite discriminar claramente los casos en que un cambio en la naturaleza del sujeto o complemento conlleva un cambio en el significado de la expresión. Sin embargo, lo realizado hasta ahora no permite discriminar de modo adecuado las variantes o limitaciones de una determinada expresión. Para ahondar sobre el tema tomemos en consideración la siguiente expresión: irse a freír espárragos. Como se sabe, el sujeto de esta locución ha de ser un sustantivo; sin embargo, de la naturaleza de dicho sustantivo va a depender el significado que porte dicha expresión:

(1) (irse) [alguien] a freír espárragos (aplicado a personas) = marcharse.

(2) (irse) [algo] a freír espárragos (aplicado a cosas) = fracasar, quebrar.

Por ello, los autores de algunos diccionarios fraseológicos, siendo conscientes del problema, han optado por establecer unas dicotomías genéricas en relación con dichas funciones sintácticas de carácter obligatorio, para dar forma a ciertas locuciones. La solución ha sido crear la dicotomía «alguien/algo», o bien «alguna persona/alguna cosa» para hacer referencia a la naturaleza del sujeto o complemento que acompaña a una expresión. Dichas dicotomías resultan no ser adecuadas cuando la semántica interna de algunas expresiones presenta restricciones que no coinciden con las citadas dicotomías. Veamos, a este respecto, algunas cuestiones que obligarían a crear un cuadro más completo de opciones, de indudable ayuda para los que deseen aprender más sobre el uso de una determinada locución.

Ciertamente, la oposición «alguien/algo» queda meridianamente clara a la hora de separar las personas de las cosas; sin embargo, la cosa no es tan diáfana al situar los animales en relación con dicha dicotomía. De hecho, desde el punto de vista gramatical la citada dicotomía no es sustantivo animado vs. no animado, sino personas (alguien) frente a cosas (algo), quedando ciertos sustantivos - los que hacen referencia a animales- en un limbo al margen de los cauces de la gramática. Este divorcio entre la bipartición gramatical y la tripartición que podríamos llamar cognitiva (personas, animales y cosas), hace que en ciertas expresiones quede invalidado o no sea aplicable lo que hasta ahora han utilizado algunos diccionarios fraseológicos, 
esto es la dicotomía alguien/algo o alguna persona/alguna cosa. ${ }^{11}$ Para solucionar dicha asimetría entre la gramática y la percepción cognitiva que se proyecta de la realidad, quizás fuera lo más oportuno crear un sistema más complejo.

Por otra parte, es cierto que la mayoría de las funciones del entorno de las UF responden al modelo, personas/cosas, sin embargo, aún siendo así, se hace necesario detallar si la expresión se monta sobre un sujeto masculino o femenino, o si una determinada expresión exige un sujeto en singular o en plural. Podría argumentarse que en ciertos casos es el propio significado de la expresión, al ser aplicable exclusivamente a seres animados o no animados, masculinos o femeninos, etc., el que determina que el sujeto sea de algún otro tipo. Siguiendo esta línea podría afirmarse que en las expresiones que caracterizan, por ejemplo, lo homosexual se hace irrelevante tal distinción, pues esto sólo es aplicable a ciertas personas -o animales- y no a las cosas.

Sin embargo, la lengua, al igual a veces que la misma realidad, presenta una riqueza de matices a la que es obligado hacer referencia. Así, en la lengua están presentes una serie de unidades que hacen referencia - por poner un ejemplo-, a la homosexualidad. Expresiones de este tipo son:

(3) Ser [alguien] del gremio

(4) Ser [alguien] de la acera de enfrente

(5) Perder [alguien] aceite

(6) Ser [alguien] de la cáscara amarga

Por lo general dichas expresiones se aplican a seres masculinos, para dar a entender que el sujeto es homosexual. En principio, por tanto, dichas expresiones no son aplicables a seres femeninos más allá de los casos de desautomatización ${ }^{12}$ en que se hace referencia al lesbianismo. Por esta razón, lo más conveniente sería hacer hincapié en los elementos del entorno que justifican dichas restricciones de uso, remarcándolos como «ser masculino», para dar a entender que también es aplicable a animales «machos», a la vez que se excluye de su uso al género femenino:

(7) Ser [un ser masculino] del gremio

(8) Ser [un ser masculino] de la acera de enfrente

(9) Perder [un ser masculino] aceite

(10) Ser [un ser masculino] de la cáscara amarga

A veces, el señalar la naturaleza de los elementos del contorno no solo responde a lo ya dicho, sino que puede ir más allá y determinar el significado de la expresión. Veamos los siguientes ejemplos:

${ }^{11}$ Tal simplificación gramatical a la hora de establecer solo dos grupos: personas (alguien) - cosas (algo) no solo afecta al marco de las UF. Una proyección de este mismo problema se observa en la inseguridad de los hablantes en relación con la a de objeto directo cuando se trata de un animal: vio el gato - vio al gato. No es de extrañar que los lingüistas, basándose en postulados gramaticales hayan justificado el uso con $a$ como una personificación del animal, mientras que un uso apreposicional conduciría a conceptuar gato como un objeto (algo).

${ }^{12}$ Termino acuñado por Zuluaga (1980) con que se hace referencia a la ruptura, por parte de los hablantes, de una UF. Nosotros aquí nos referimos a una ruptura en el ámbito del contenido al aplicar dicha UF a sustantivos no predispuesto a ello en su uso «normal». 
(11) Ser del gremio

(12) Ser ligero de cascos

En ambos casos el significado de la expresión va a estar mediatizado por los elementos del entorno. La primera UF señalada, ser del gremio, puede portar dos significados, por lo que será el elemento del entorno el que se erija como elemento discriminador. Así, mediante la expresión ser [un varón] del gremio se hace referencia a que dicha personas es «homosexual», mientras que si se aplica a mujeres ser [una mujer] del gremio pasará a significar «prostituta».

Algo similar ocurre con ser [alguien] ligero de cascos. La información del elemento del entorno es claramente insuficiente, puesto que su significado va a estar en función de que lo apliquemos a una mujer o a un hombre. Así, aplicado a una mujer tiene el significado de 'frívola, libertina, inmoral'; mientras aplicado a varones significa, normalmente, 'informal e irreflexivo'. ${ }^{13}$ Ello no es óbice para que, en determinados casos, haya un trasvase de los contenidos que atañen a ambos sexos, pero esto habría que atribuirlo más a aspectos lúdicos del lenguaje que a al contenido propio de la expresión.

En lo que respecta al número en los elementos del entorno, hemos detectado que los diccionarios recurren a la forma no marcada del singular ponerse [alguien] morado, vivir [alguien] del cuento, etc., para dar a entender que tales expresiones son susceptibles de ser usadas, también, en plural: los niños se pusieron morados, aqui todos viven del cuento. No obstante, podemos encontrar expresiones en las que la citada función está obligada a parecer en plural, como se observa en los siguientes ejemplos:

(13) Caer [personas-animales] como chinches

(14) Ser [alguien-plural] uña y carne

(15) Darse [alguien-plural] de bofetadas para [algo]

por lo que debería quedar claramente remarcado.

Caso aparte dentro de este grupo es el formado por unidades que admiten las dos formulaciones -en singular y en plural-, pero con una particularidad que los diferencia de lo expuesto más arriba. Así, antes hemos comentado que la formulación en singular de estas funciones obligatorias no fijadas es la forma no marcada, que abarca el plural cuando ello no representa un cambio de significado: Él hace el paripé frente a Ellos hacen el paripé. Sin embargo, ello no es así en unidades del tipo andar [alguien] a la greña frente a andar [alguien-plural] a la greña. En el primer caso, el sujeto en singular hace referencia a la persona que 'busca polémica o enfrentamiento con un tercero'. En el segundo caso - con sujeto en plural-, no se hace referencia a personas que buscan enfrentamiento con un tercero, sino a personas que buscan enfrentamiento entre sí. No se puede decir que en ambas unidades haya un significado diferente, pero sí que hay un matiz de acción recíproca que es necesario reseñar. Nos parece por tanto oportuno remarcar esto estableciendo dos unidades diferenciadas en el diccionario, o bien hacer referencia clara al matiz que representa un sujeto plural en dicha expresión.

Más complejo aún para un estudiante de español como lengua extranjera es el aprendizaje de expresiones fijas polisémicas, o de aquellas que con retoques mínimos en la estructura

${ }^{13}$ No obstante lo dicho, pueden observarse ciertas absorciones semánticas de un género sobre el significado del otro y viceversa. Pese a todo, ello no suele suponer ambigüedad o malentendido si se insertan en un contexto idóneo. 
pasan a significar cosas completamente diferentes. Ya hemos reiterado que no pocas veces son los elementos del entorno locucional los que determinan el significado de la expresión. Sin embargo, en ocasiones los diccionarios ignoran esta regla considerando que un cambio en la naturaleza del sujeto o el complemento sólo conlleva una actualización siguiendo las reglas «naturales» de la lengua; esto es, poniendo en marcha el proceso de actualización o selección que se utiliza en la combinación de los componentes monoverbales de la lengua. $\mathrm{Y}$, en cierto modo, esto es así en algunos casos; así dejar [alguien] como un colador [a alguien] no difiere mucho semánticamente de dejar [alguien] como un colador [algo]. El punto en común sería el «causar muchos agujeros», si bien, en el caso humano, lo normal es que sea a consecuencia de disparos. La distancia semántica entre una y otra acepción es fruto de un moderado desplazamiento, por lo que el conocimiento de una formulación puede llevar a descifrar semánticamente la otra. Sin embargo, otras veces el conocer una formulación no allana el proceso para conocer otra similar. Pongamos el caso de estas dos expresiones en su uso más general:

(16) Tener [alguien] cojones $=$ ser valiente

(17) Tener [algo] cojones $=$ ser difícil

No parece que haya operación que permita hablar de desplazamiento semántico. Más bien se puede hablar, a priori, de expresiones sincréticas. Para poder precisar el desplazamiento de lo humano a lo más general (que ya atañe a cosas) hay que recurrir a otro significado: nos referimos a la expresión cuando se aplica a niños. Así, el niño del vecino tiene cojones no significa que sea 'valiente', sino que es 'maleducado, difícil'. Éste parece ser el significado que, originado en una estructura «racional» (sólo un ser animado puede tener cojones), es desplazado hacia formulaciones más amplias, pese a carecer de la racionalidad original.

Hechos como los subrayados, que no se recogen en los apartados de los diccionarios de lengua dedicados a la fraseología, ni en los diccionarios fraseológicos ex profeso, deberían ser tratados en profundidad con el fin de dar mayor precisión al significado de las locuciones.

\section{CONCLUSIONES}

Como resumen, puede decirse que, pese de los esfuerzos ya realizados en la lexicografía fraseológica, cuyos frutos van apareciendo poco a poco, parece necesario profundizar más en la metodología que afecta a dicho campo, y no solo en cuanto a la peculiar estructura de estas unidades, sino teniendo en cuenta los naturales usuarios de un diccionario. En este sentido, parece conveniente, en primer lugar, un estudio de los componentes de cada estructura, teniendo en cuenta ciertos elementos formales -como son los elementos del contorno- que, por sí mismos discriminan automáticamente los significados. Esta distinción ha de ser lo más precisa posible con el fin de evitar que una expresión o el significado de ésta se aplique a un sustantivo que, por su propia naturaleza, no esté capacitado para dicho uso. Por esta razón, a nuestro juicio, no se trata de expresiones polisémicas, sino de estructuras sincréticas que funcionan con diferentes elementos del contorno y que constituyen verdaderos signos diacríticos a la hora de establecer las diferencias entre una unidad y otra.

En lo que respecta al contenido, la realización de estudios contextuales en el ámbito locucional podría determinar los diferentes sentidos, así como las tendencias que ya estén en marcha. 
Es importante, por último, a la hora de confeccionar un diccionario fraseológico de producción, tener en cuenta que el proceso de memorización ha de estar lo más unido posible a su uso práctico. Por ello, además de los enunciados en que se usa correctamente una unidad es importante subrayar en el mismo lema, las restricciones de uso que el hablante ha de tener en cuenta en el momento de usar una determinada expresión fija.

\section{REFERENCIAS BIBLIOGRÁFICAS}

Ahumada Lara, I. (1989): Aspectos de lexicografía teórica. Aplicaciones al Diccionario de la Real Academia Española, Granada, Universidad de Granada.

Butrrago, A. (2002): Diccionario de dichos y frases hechas, Madrid, Espasa.

CALDERÓn, M. (1994): Sobre la elaboración de diccionarios monolingües de producción, Granada, Universidad de Granada.

CASARES, J. (1992 [1950]) Introducción a la lexicografía moderna, Madrid, CSIC..

Castillo Carballo, M. A. (2001a): «La fijación sintagmática en el diccionario», en E. Méndez, J. Mendoza y Y. Congosto, eds., Indagaciones sobre la lengua: estudios de filología y lingüística españolas en memoria de Emilio Alarcos, Sevilla, Universidad de Sevilla, pp. 395-416.

_ (2001b): «Unidades fraseológicas y diccionarios: aplicaciones didácticas», en M. C. Ayala Castro, coord., Diccionarios y enseñanza, Alcalá de Henares, Universidad de Alcalá, pp. 151-161.

Cifuentes, J.L. (1994): Gramática cognitiva. Fundamentos críticos, Madrid, EUDEMA.

Corpas Pastor, G. (1996): Manual de fraseología española, Madrid, Gredos.

Domínguez, P. et al. (1988): El español idiomático. Frases y modismos del español, Barcelona, Ariel.

DUE. M. Moliner (1977): Diccionario de uso del español, Madrid, Gredos.

Fernández-Sevilla, J. (1974): Problemas de lexicografía actual, Bogotá, Instituto Caro y Cuervo.

García-PAge, M. (2000): «Expresiones fijas idiomáticas, semiidiomáticas y libres», Cahiers $d u$ P.R.O.H.E.M.I.O., 3, pp. 95-109.

(2001): «¿Son las expresiones fijas expresiones fijas?», Moenia 7, pp. 165-197.

GDLE. A. SÁNCHEZ, coord. (1985): Gran Diccionario de la lengua española, Madrid, SGEL.

Hausmann, F. J. (1979): «Un dictionnaire des collocationsest-il possible?», Travaux de linguistique et de Litterature, 17/1, pp. 187-195.

LARA, L. F. (1979): «Del análisis semántico en lexicografía», en L. F. Lara, R. H. Chade y M. I. García Hidalgo, Investigaciones lingüísticas en lexicografía, El Colegio de México, México, pp. 157266.

Martín SÁnchez, M. (1997): Diccionario del español coloquial. Dichos, modismos y locuciones populares, Madrid, Tellus. 
MARTínez Marín, J. (1991): «Fraseología y diccionarios modernos de español», Voz y Letra, iI/ 1, pp. 117-126.

PENADÉs, I. (1999): La enseñanza de las unidades fraseológicas, Madrid, Arco/Libros.

ReY-Debove, J. (1994): «La lexicografia moderna», Voz y Letra, v/1, pp. 31-45.

Ruiz GuriLlo, L. (1997): Aspectos de fraseología teórica aplicada, Valencia, Universidad de Valencia.

- (2000): «Cómo integrar la fraseología en los diccionarios monolingües», en G. Corpas Pastor, ed., Las lenguas de Europa: estudios de fraseología, fraseografía y traducción, Granda, Comares, pp. 261-274.

VARela, F. y H. Kubarth, H. (1994): Diccionario fraseológico del español moderno, Madrid, Gredos.

WотנAк, G. (1985): «No hay que estar cruzado de brazos. Algunas observaciones acerca del significado de expresiones idiomáticas verbales del español actual», Anuario de Lingüística Hispánica, 1, pp. 213-226.

Zuluaga, A. (1980): Introducción al estudio de las expresiones fijas, Frankfurt, Peter Lang. 